\title{
Impact of Individual Decision-Making Styles on Marketing Information System Based Decision-Making: An Empirical Study of Saudi Arabia Manufacturing Firms
}

\author{
Alowaidi Mahmoud Ghazi A, Wang $\mathrm{Hu}$ \\ School of Management, Wuhan, China
}

\begin{abstract}
2016 Research Leap/Inovatus Services Ltd.

All rights reserved.

DOI: $10.18775 /$ jibrm.1849-8558.2015.13.3003

URL: http://dx.doi.org/10.18775/jibrm.1849-

8558.2015.13.3003

Keywords:

Management information system (MIS)

decision-making

decision-making styles

marketing performance

marketing innovation

Saudi Arabia

The present research was conducted on the subject on how various managerial traits have an impact on overall decision-making based on marketing information systems. The variables that were tested in order to verify if the relationship between the variables was important were rational decision-making, intuitive decision-making, dependent decision-making, avoidant decision-making, spontaneous decision-making, decision-making speed and finally decision quality. The comprehensive conclusion to the study was that the decision quality variable of information system use positively influences incremental marketing innovation and radical marketing innovation, exhibiting a distinct and significant connection. The research was conducted in Saudi Arabia manufacturing companies, allowing us to gain valuable insight and information on the present situation of the Saudi Arabia manufacturing industry and allowed us to acquire new knowledge on the marketing information systems in Saudi Arabia companies. In our hypothesized model, we investigated and analyzed the different personality traits on all managerial level of firms and organizations in Saudi Arabia and the direct influence on the aforementioned companies. The findings suggest that quality of decisions is a most significant factor of our model for marketing innovation, therefore managers must focus on improving this segment Saudi Arabia manufacturing companies. Decision making styles are partially relevant for decision speed and quality based on marketing information systems, however, they are not significantly relevant. Although IT has been implemented, the use of it has to be further promoted, with employees trained to achieve optimal organizational outcomes.
\end{abstract}

\section{Introduction}

The marketing information system within companies is mainly universal, which means that the system is not specifically tailored to meet the requirements of different managerial levels. In the past marketing information systems have been widely explored. Most of the studies, however take a solely informational perspective. The most effort is exerted into understanding of the particular technical features of the system and the way information is gathered, processed and utilized. For example, according to Delone and Mclean, the IT industry in the Middle East has matured in terms of infrastructure and solutions, but it is short on talent. According to Jobber, D and Fahy J. (2006), they propose that marketing decision-making of managers, is affected by their "marketing intuition", which reflects their experience and knowledge in the field of marketing. They state that "the purpose of decision making as well as a planning is to direct human behaviour and effort towards future objectives."

The marketing information systems which aid the decision making process always have the same output in displaying information, but why so, if different output is required in different occasions. The marketing information system has to help managers to foresee the decision about to be made and try to anticipate the possible outcome. According to
(McDonald, M. 1996) the marketing information system has to be precise and efficient to properly influence all managerial levels in making the right and appropriate decision. Making the right choice or decision is often very difficult to achieve as the individuals, or in this case company managers making the decisions have to include other factors in process of decision making, such as experience and judgment, which may or may not overlap but definitely influence the decisions being made. The decision-making process can be conceptualized with different styles, namely avoidant, spontaneous , rational,

In our study we aim to explain whether manager characteristics influence marketing information system based decision making. Light will be shed on what kind of characteristics guide decision making to produce favorable marketing outcomes and organizations suggested on how to effectively foster marketing information system decision making.

The main research questions are therfore: What decisionmaking styles are most significant for decision making based on marketing information systems? And "Do decision quality and speed made on the basis of marketing information system impact marketing innovations?" 


\section{Literature Review and Model Construction}

Much prior studies focused on a broad measure of decisionmaking styles (Scott \& Bruce, 1995) and personality (Goldberg, 1990; Goldberg et al., 2006). However, other measures of decision-making styles and personality have been found to be related (Biaocco et al., 2009; Boukenooghe et al., 2007; Epstein et al., 1996; Pacini \& Epstein, 1999) and could be examined. Various sets of decision-making styles have previously been found to relate to decision-making quality (e.g. Singh \& Greenhaus, 2004). Additionally, several personality traits have been examined as predictors of decision-making quality as well (Davis et al., 2007; Franken \& Muris, 2005). Another interesting future direction could involve expanding the scope of traditional decision-making styles. Gati et al. (2010) mentioned approaching the measurement of decision-making styles with a multi-faceted approach. Their recommended "decision-making profiles" recognize that people are influenced by a variety of factors that may result in the use of several styles, as opposed to one primary style. This view appears to align with Kahneman's (2003) situational perspective of decision styles, as well as several other researchers who have conceptualized decision-making styles as fluid, circumstantial characteristics (e.g. Galotti et al., 2006). Although decision-making styles are convenient for research purposes, tailored decision-making style profiles are potentially more useful in applied situations for guiding the development of solutions to decision-making problems and providing suggestions for future behavior modification. human aspect is still crucial in the process of making decisions, especially when it comes to decisions that are more complex. It is at that moment that decision-making styles, which stem from individual distinctiveness of the decision maker, may influence the process of decision-making in contrast to when it comes to routine decisions. For instance, an individual characterized by a spontaneous decision-making style is inclined to make impulsive and "instant" decisions. Their desire to get through the decisionmaking process as quickly as possible (Spicer and Sadler-Smith, 2005) may jeopardize the quality of the decisions made. In order to lessen an impact of the human factor, a marketing information system should be constructed to eliminate the individual differences of decision-makers in terms of their decision-making styles. This can be achieved through an informational output with certain recommendations, suggestions and possible scenarios, as well as decision outcomes.

Drawing from the decision analysis and information system literatures, we present a typology of decision-making styles and elaborate the existence relationships with decision information system use. A number of linkages exist in this setting: rational, spontaneous, intuitive, avoidant and dependent on the quality and speed of information system use. Significant differences in all aspect-related dimensions are directly shown across the five decision making types. The study model improves the understanding of the different types of decision making types and their process outcomes particularly on marketing innovation. Decision making styles on information system use scenario does not necessarily follow traditional decision behavior due to rapid changing of information technologies from time to time which the focus is on the speed but not necessarily compromising the quality of decision.

\subsection{Impact of decision making styles on information system use \\ 2.1.1 Spontaneous}

Time is regarded as a scarce managerial source which makes choice pace an significant consideration in organizational decision processes which complements the information system use. Managers (decision makers) prefer time-based which are more temporary efficiency of achieving particular objectives and results because it indicates flexibility of an organization to through quality and speed of decisions to lessen an organization's exposure to the uncertainties of external environment (Angwin, 2004). Spontaneous decision making rely on impulsive and individuals are more likely "spur-of-the-moment" or "instant" decisions. According to this we can hypothesize that marketing conditions that involve speedy decisions are better handled by individuals that fit under impulsive decision making method. Persons in this manner are described by a feeling of closeness and the desire to get through or succeed over the deciding as quick as possible (Spicer, and Sadler-Smith, 2005). Prior studies on decision speed view prompt action as a decisive competitive weapon for market innovation and similar studies added by suggesting that speed of decision does not lessen the quality of decision and that longer time taken to make a decision do not essentially guarantee or boost decision correctness (e.g. Hickson, Butler, Cray, Mallory, \& Wilson, 1986). As to how an organization and individuals are able to make such quick decisions is affected by factors within their internal and external environment streamlined toward market innovation. Decision speed achieved by spontaneous decision making style can be a source of competitive edge in the light of subsequent empirical prescriptions of the pursuit of marketing innovation (Bourgeois \& Eisenhardt, 1988). Decision-making styles, a sub-component of cognitive styles (Kozhevnikov, 2007). This background discussion brings the development of the following hypotheses;

Hla: Spontaneous decision making style positively influence decision quality

H1b: Spontaneous decision making style positively influence decision speed

\subsubsection{Intuitive}

The impact of using an intuitive approach onto information system use decision making which is basically on quality and speed of decision is based primarily on self-awareness rather than relevant collected information (Blustein, 1987). Whilst intuition is likely to include spontaneous decision making style, an individual feels they have ended a problem or decision on the level of control they possess toward solving such problem or making a decision (Phillips et al., 1984). The speed of decision is swiftly and this is an important scenario of this type of decision making necessary for capturing opportunities of strategic windows in context of marketing innovation. Intuitive decision making style earned much popularity in the recent years to contribute quick decisions as organizations in recent times rely heavily prompt service delivery which makes intuitive an 
important aspect of decision speed although its imprints can be traced back to Chester Barnard (1938). According to Patton (2003) there are three sources of intuition used by decision makers when they are trying to handle the uncertain and volatile situations of making a decision due to rapid and complex changes in the setting. Firstly, is innate response of decision making which is overseen on decision maker's instinct that bring subconscious but usually the reactions are still suitable and applicable to situations that a decision is required to be made. It is inborn and not a learned reaction. Secondly, general experience involves learning that happens in the normal process of aging in a person's life and of accumulating experience in the process. Finally, focused learning which revolves on learning that stems from deliberate effects to develop habits and achieve intuitive reactions. All these affect the decision quality and the speed at which such decisions are made are a result of these habits and inborn characteristics of the decision maker. Pacini and Epstein (1999) took the well-established distinction made between System 1 (i.e. intuitive) and System 2 (i.e., conscious/rational) processing and thinking (Hodgkinson, Langan-Fox, \& SadlerSmith, 2008; Johnson-Laird, 1983; Stanovich \& West, 2000), and developed the Rational-Experiential Inventory (REI) to measure the tendency of people to rely on these two types of thought. The following hypotheses are developed based on the above discussion;

\section{H2a: Intuitive decision making style positively influence decision} quality

H2b: Intuitive decision making style positively influence decision speed

\subsubsection{Rational}

Consistent with a Parsonian perspective that argue that decision making styles are strategies for solving problems, a rational style which encompasses active and well calculated plans of decisionmaking activities-has been proposed as an ideal strategy (Larson, 1987). Nonetheless, study partially supports this hyphotesis. numerous papers that studied the association between a rational style and progress in decision making on tasks shown positive or insignificant results (Harren, Kass, Tinsley, \& Moreland, 1978; Lunneborg, 1978; Phillips, Pazienza, \& Walsh, 1984). Individuals that are in rational decision making style forestall the need to make a decision and prepare for it by seeking relevant information about themselves and their environment before committing to a particular decision. This process has an influence on decision quality of which the probability is high in making an informed quality decision, however the speed of decision is likely not to be prompt because of the time span required in information gathering. In rational decision making style an individual's main approach to gathering the information and processing it to capture only relevant details is systematic and oriented toward both internal and external sources which contributes heavily to the decision quality that consequently leads to marketing innovation (Thunihohm, 2004).

For that reason we investigate in this model the function and importance of modern information system resources and access as a successor for the structuring of the strategic decision-making process from different cognitive styles of individuals in making decisions. We scrutinized in detail the utilization of information system during the process of a number of actual recent tactical decisions employed by executives in the in diverse industries. The emphasis is on the process of the decision making, not on the substance of the resulting decisions, i.e. marketing innovation.

Hence, the rationality is in the essence of selecting which information to select and analyze and which ones to overlook (Choo, 2006; Citroen \& Hooghoff, 2003; Hussey, 1997; Schwenk, 1986). The of the decision-making process structured approach is described by the fact that the decision is made following an wide search in due attention with a number of distinctive phases that are orderly timed and that can be observed and examined in a rational and objective way to increase the quality of decision. Thus far, we can hypothesize that;

\section{H3a: Rational decision making style positively influence decision quality \\ H3b: Rational decision making style positively influence decision speed}

\subsubsection{Dependent}

The decision maker in dependent type of decision making puts reliance upon others for the direction and support. As a team working toward a general aim this type of decision making is good for interpersonal and intrapersonal which is more of a participative decision making which results in a more quality decision. Additionally, the decision might not be quick due to reliance and consultation on others before a final decision is made, however such decision are less likely to be resisted as other individuals are consulted and aware of the possible outcome of the decision. Dependent decision makers always look for suggestion and direction from others before reaching important decisions (Thunihohm, 2004). Hennig-Thurau et al. (2007) demonstrated that the information provided by means of information system such as the online forums is very influential toward marketing innovation. This is substantiated by market research. As mentioned earlier, dependent decision making style relies on others for final decision which is more of participatory process which can result in the development of more innovative solutions to issues through the insertion of a variety of different perspectives (Brody, 2003; Coenen, 2008; Layzer, 2008; Fritsch and Newig, 2012) and the integration of different types of knowledge (Fung, 2006) in decision making necessary to improve the decision speed and quality. Dependent decision making style accommodates the open dialog and the provision of sufficient time for genuine exchange of ideas and reflection on the part of the participants and are thereby significant because of their also conduciveness to the emergence of creative, positivesum solutions toward marketing innovation (Heinelt, 2002). Marketing advance can be both optimistic and pessimistic concerned by the standard of a decision which is highly dependent on the environment of any cooperation between expected reimbursement and other size of the wellbeing of stakeholders, which is likely to be formed by the particular interests and priorities of the decision participants and 
stakeholders. In this sense, the influence of marketing interests and the provision of knowledge in a dependent decision-making process are significant causal factors for the development of marketing innovative solutions. We therefore develop the following hypotheses;

\section{H4a: Dependent decision making style positively influence decision quality}

H4b: Dependent decision making style positively influence decision speed

\subsubsection{Avoidant}

The avoidant style is the propensity to evade decisions each possible time. Avoidant style is related to low self-regulation ability, low self-esteem, and problems with taking initiative (Thunholm, 2004). In other words, individuals with this approach do not want to believe or select among alternatives, and thus fail to undertake the decision. A verdict cannot be prepared if one does not start the procedure. Furthermore, Bruine de Bruin et al. (2007) found negative correlations between their behavioral measure of decision-making quality and the avoidant decisionmaking style measured with Scott and Bruce's (1995) GDMS measure.

Avoidant decision-making style is very similar to the construct indecisiveness. The study by Diab, Gillespie, and Highhouse (2008) showed a fairly strong correlation between avoidant decision-making style and a common measure of indecisiveness. Indecisiveness has been defined as being stuck in the decisionmaking process, unable to make a choice, which causes negative emotions (e.g. stress and anxiety) (Elaydi, 2006). Indecisiveness has been theorized to hinder decision making in three ways: lacking information about options, valuation problems, and how each alternative relates to one's desired outcome. The previously mentioned studies support a negative relation between avoidant decision-making style and the reason-based decision-making quality. Avoidant decision-making style attempts to evade decision making altogether (Scott \& Bruce, 1995). Avoidant decision-makers do not want to attempt to find a solution or consider alternatives available. However, reason-based decisions call for using previously acquired knowledge to determine the best solution (Simon, 1987). People who have the knowledge and skills to quickly make a decision do not avoid the situation, and therefore, avoidant decision-making style will be negatively related to performance on reason-based decision-making and thus producing nothing for marketing innovation. We can hypothesize that;

H5a: Avoidant decision-making style negatively influence the decision quality.

H5b: Avoidant decision-making style negatively influence the decision speed.

\subsubsection{Decision quality}

Quality of decision from information system use influences the marketing innovation in a variety of ways. The decision-maker evaluates the value of an information system and direct it toward desired objectives. The information systems literature is rich in studies on the use of information system as a competitive weapon, i.e., toward the development of marketing innovation. The studies indicate importance and crucial role that information system plays in marketing innovation. At the same time, studies in the international business literature have examined the strategic forces affecting competition at a global scale as compared to domestic competition and have shown the differences between these and the competitive forces faced by domestic corporations. It seems, however, that both the management information system and the international management literature have recognized the significance of information system use of quality decisions that are derived from the use of quality information as a facilitator for gaining competitive advantage through marketing innovation in the international environment (Deans and Ricks, 1991). According to Jarvenpaa and Ives (1993) information system is needed to drive marketing innovation activities in a global organization's structure and strategy. Therefore, managing quality decisions about marketing information by means of information system has become one of the most vital elements of driving effective marketing innovation. Board success and failure is largely dependant on the speed and quality of made decisons (Mc Gregor, 2010).Quality of the decisions is mainly determined by identification of goals, availabilty of alternatives for problem solving and measuring the values and interests (Flueler and Blowers, 2007). the quality of domain-specific decisions such as predicting the results of soccer matches (Cattell, Eber, \& Tatsuoka, 1970) or making appropriate medical choices regarding the treatment of a medical condition (Hagger, Wood, Stiff, \& Chatzisarantis, 2010).

In a number of papers, quality of information iss regarded as crucial part of users satisfactio. Accuracy, completeness, relevance and timeliness is the important attributes that determine quality of information. IS department service excellence offers relational and industrial contexts in which the employees interpret behaviors and events linked to the system satisfaction. Hamidi, and Safabakhsh (2011) posit that information systemquality based decision on marketing information systems is important to support marketing management in its decision making which can be aimed toward marketing innovation. Besides the importance of information system use- quality decision to the management perspective, it can be an essential tool for the entire marketing organization. Some scholars have classified information system in marketing by the tasks for which they are typically used (e.g., Wierenga, 1990). Information system use: decision quality was used by Wierenga (1990) to develop a framework of marketing and sales productivity (MSP) systems which comprises of four subsystems namely the salesperson productivity tools, direct mail, telemarketing and sales management. This can be viewed as marketing innovation through use of information system which dictates the realization of quality decision. Therefore, we hypothesize that;

H6a: Decision quality of information system use positively influence marketing innovation 


\subsubsection{Decision speed}

In dynamic and rapid changing markets, organizations cannot afford to rely on slow or rather relaxed decision making process if ought to achieve market innovation in order to outperform competitors. Therefore, achieving market innovation in such environments requires decisions to be speedy. In the study by Bourgeois and Eisenhardt (1988), the pivotal feature of decision processes is identified in its advantageous effect on organizational performance (i.e. market innovation. Many scientists have studied how decision rate is formed by scope of individual distinctiveness of decision makers, decision specific factors, and the external environment. Bourgeois and Eisenhardt (1988) discovered that speed of decision is crucial point of decision speed, which identified its beneficial effect on firm performance. Since that time, researcher have started to scrutinize speed of decision as a competitive advantage and to examine how it is formed by scope of organizational structure, personal characteristics of decision makers, decision specific factors, and the external environment. The above mentioned structural dimensions consist of decision process centralization, formalization, and organizational polychronicity (i.e. a culture favoring simultaneous multi-tasking).

Hb: Decision speed of information system use positively influence marketing innovation

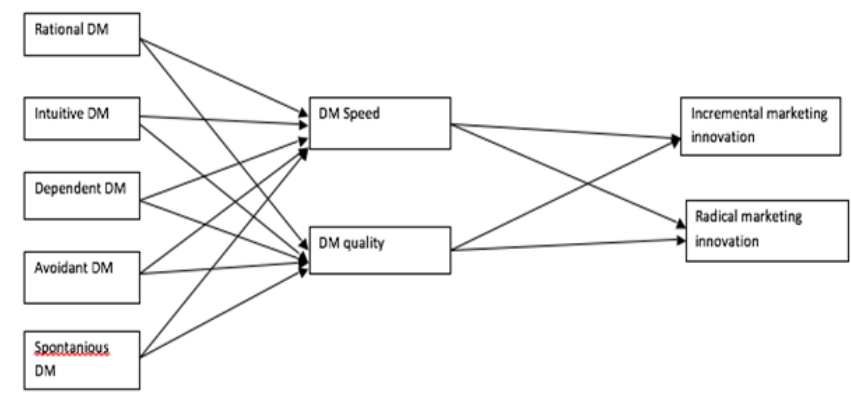

Figure 1: Research model

\section{Methodology And Results}

Both inductive and inductive approaches were used, as we needed to explore the situation within companies on whether they use the marketing information system and explain the relationships between different variables and after we explained the relationships and closely analyzed and interpreted the relationship between the variables.A deductive approach was used to determine the influence of the marketing information system on decision-making. The deductive approach can be described by the means of hypotheses, which can be obtained from the premises of the theory. The variables that were tested in order to verify if the connection was substantial were rational decision-making, intuitive decision-making, dependent decisionmaking, avoidant decision-making, spontaneous decision-making, decision-making speed and finally decision quality.
Table 1: Descriptive statistics

\begin{tabular}{|c|c|c|c|c|c|c|}
\hline Variable & Mean & Std. Deviation & Skewness & Kurtosis & Minimum & Maximum \\
\hline Incremental marketing innovation & 4,1277 & .74793 & $-9,918$ & .633 & 2,00 & 5,00 \\
\hline RADICAL INNOVATION & 4,1897 & .68810 & -762 & ,335 & 2,00 & 5,00 \\
\hline Rational DM & 4,4681 & .60646 & $-2,300$ & 10,229 & 1,00 & 5,00 \\
\hline Intuitive DM & 3,5340 & 85024 & -336 &,- 533 & 1,60 & 5,00 \\
\hline Dependent DM & 3,9915 & 63782 &,- 469 &,- 302 & 2,40 & 5,00 \\
\hline Avoidant DM & 2,7021 & 1,10512 & .217 &,- 708 & 1,00 & 5,00 \\
\hline Spontanious DM & 2,9298 & 99966 & .074 & -547 & 1,00 & 5,00 \\
\hline Decision making speed & 4,2660 & 75028 & -1516 & 3,799 & 100 & 5,00 \\
\hline Decision quality & 4,0399 & 73534 & $-1,048$ & 2,419 & 1,00 & 5,00 \\
\hline
\end{tabular}

When testing for normality, are main concern was the Normality table and the Normal Q-Q Plots, and the numerical and graphical approaches to test for the normality of data. The statistical results was performed using two tests of normality, the KolmogorovSmirnov Test and the Shapiro-Wilk Test.

As a part of normality tests Kolmogorov-Smirnov indicators were calculated with values ranging from 0,097 to 0,223 . Intuitive decision-making style exhibited the lowest value $(0,097)$ and decision-making speed reported the highest value. Furthermore, Shapiro and Wilk Tests showed that all values were above 0,782 . The maximum value of 0,982 was calculated for spontaneous decision making whereas the minimum of 0,782 was reported for rational decision-making. The Shapiro-Wilk test is generally used for smaller samples, but we included it in our study since our sample was within the range this test is normally used. To validate the results of both normality tests an evaluation of qq plots was performed.

\subsection{Reliability and validity assessment}

The reliability was tested for all variables to determine internal consistency. Reliability was used to determine how much the items on a scale are measuring the same underlying dimension. Reliabilty characterized the extent to which all the measures in a analysis examine the same concept or construct and hence it is linked to the relation of the measures within the test. Internal consistency should be prepared before a test can be employed for research or examination purposes to ensure validity. Furthermore, , reliability displays the amount of measurement error in a test. All the items were measured using a seven-point Likert-scale Cronbach's Alpha for the avoidant decision-making item was 0.914, which exhibited sufficient reliability. The dependent decision-making style item exhibited the lowest value $(\alpha=0.643$ ), which in the end demonstrated a sufficient degree of reliability. Radical marketing innovation reported the highest Cronbach's Alpha $(\alpha=0.938)$ and incremental marketing innovation also exhibited a large value $(\alpha=0.925)$. All the reported items of the present scale demonstrated relatively high coefficients of reliability, suggesting that the items have a high internal consistency but a high coefficient of reliability did not necessarily imply that the scale was unidimensional.

In our study, we assessed the validity of our model and the hypothesized variables. This included generating and testing the propositions and equaling the causal conditions that exist. We posed the question whether our research measured the intended object and checked the internal validity. We also analyzed to what extent are the abstract constructs and postulates generated 
and tested by our scientific research applicable across groups, which was classified as external validity and checking the consistency of findings produced by different data collection methods and of different data sources within the same method. For each type of construct validation research, appropriate methods and quantitative models are performed to test a priori hypotheses concerning construct validity. Finally, for construct validity to exist, there needs to be a definite link between the construct and the measures and interventions that are employed to operationalize it. In our research, a precise and clear distinction was reported between different constructs. The Kaiser-Meyer-Olkin Measure of Sampling Adequacy (KMO) was 0.795 and the Bartlett's Test of Sphericity had a $\mathrm{p}=0$.

\section{Structural model analysis}

The correlation between variables was measured using a linear correlation coefficient, which measures the strength and the direction of a linear correlation between two variables. Any type of correlation that is above 0.8 , can be considered as a strong linear correlation, while on the other hand, if the linear correlation coefficient is below 0.5 , the analyzed item is described as weak and inadequate.

Table 2: Correlation table

\begin{tabular}{|c|c|c|c|c|c|c|c|c|c|c|}
\hline Variable name & & 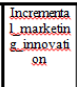 & \begin{tabular}{|c|} 
RADICAI \\
MARKE \\
INNG IN \\
NOATIIO \\
N
\end{tabular} & $\begin{array}{c}\text { Rational. } \\
\text { DM. }\end{array}$ & $\begin{array}{c}\text { Intuitive } \\
\text { DM }\end{array}$ & \begin{tabular}{|l|l|} 
Dependent \\
-DM
\end{tabular} & $\begin{array}{c}\text { Avoidant } \\
\text {-DM }\end{array}$ & $\begin{array}{c}\text { Spontaniou } \\
\text { s.DM } \\
\text { S.DM }\end{array}$ & \begin{tabular}{|c|} 
Decision \\
making \\
eed
\end{tabular} & $\begin{array}{l}\text { Decision_m } \\
\text { quality } \\
\text { qual }\end{array}$ \\
\hline & $\begin{array}{l}\text { Pearson } \\
\text { Corelation }\end{array}$ & & $.795^{\circ}$ & .042 & .172 & .120 & $209^{\circ}$ &, 144 & $391^{\prime \prime}$ & .555" \\
\hline \multirow{3}{*}{ 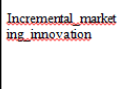 } & Sig. (2-tailed) & &, 000 & 686 & 098 &, 251 &, 044 &, 166 &, 000 &, 000 \\
\hline & $\mathrm{N}$ & 94 & 94 & 94 & 94 & 94 & 94 & 94 & 94 & 94 \\
\hline & Pearson &, $795^{*}$ & 1 & .061 &, 105 & ,199 & 159 &,- 025 &, $503^{*}$ & $596^{* *}$ \\
\hline \multirow{3}{*}{$\begin{array}{l}\text { RADICAL_MARK } \\
\text { ETING_INNOVAT } \\
\text { ION }\end{array}$} & $\begin{array}{l}\text { Correlation } \\
\text { Sig. (2-tailed) }\end{array}$ & .000 & & .562 &, 314 & .055 & .125 & 809 & .000 & .000 \\
\hline & $\mathrm{N}$ & 94 & 94 & 94 & 94 & 94 & 94 & 94 & 94 & 94 \\
\hline & $\begin{array}{l}\text { Pearson } \\
\text { Correlation }\end{array}$ & 042 & 061 & 1 & $: 106$ &, 133 & $-268^{*}$ & -128 &, 106 &, 164 \\
\hline \multirow[t]{3}{*}{ Rational_DM } & Sig. (2-tailed) & .686 & .562 & & 308 & .202 & ,009 & .218 &, 308 &, 115 \\
\hline & $\mathrm{N}$ & 94 & 94 & 94 & 94 & 94 & 94 & 94 & 94 & 94 \\
\hline & $\begin{array}{l}\text { Pearson } \\
\text { Correlation }\end{array}$ & ,172 & ,105 & , 106 & 1 &, $277^{*}$ & .381" & ,484" & ,144 & 151 \\
\hline \multirow[t]{3}{*}{ Intutitive_DM } & Sig. (2-taled) & .098 & 314 & .308 & & ,007 & ,000 & .000 & , 166 &, 145 \\
\hline & $\mathrm{N}$ & 94 & 94 & 94 & 94 & 94 & 94 & 94 & ${ }_{94}$ & 94 \\
\hline & Pearson & ,120 & |199 & 133 &, $277^{*}$ & 1 & $.336^{*}$ & .185 & ,171 &, 167 \\
\hline \multirow{3}{*}{ Avoidant_DM } & $\begin{array}{l}\text { Conelation } \\
\text { Sig. (2-taled) }\end{array}$ & , 044 & , 125 &, 009 & , 000 &, 001 & & , 000 & .607 & ,196 \\
\hline & $\mathrm{N}$ & 94 & 94 & 94 & 94 & 94 & 94 & 94 & 94 & 94 \\
\hline & Pearson & ,144 &,- 025 &,- 128 & , 484" & ,185 & ,628* & 1 &,- 025 &, 076 \\
\hline \multirow[t]{3}{*}{ Spontarious_DM } & $\begin{array}{l}\text { Correlation } \\
\text { Sig. (2-tailed) }\end{array}$ &, 166 & .809 &, 218 & .000 & .075 & .000 & & .811 & .469 \\
\hline & $\mathrm{N}$ & 94 & 94 & 94 & 94 & 94 & 94 & 94 & 94 & 94 \\
\hline & Pearson & $391^{*-}$ &, $503^{*}$ &, 106 & 144 &, 171 & 054 & $-0,025$ & 1 &, $755^{*}$ \\
\hline \multirow{3}{*}{$\begin{array}{l}\text { Decision_making S } \\
\text { peed }\end{array}$} & $\begin{array}{l}\text { Corelation } \\
\text { Sig. (2-tailed) }\end{array}$ &, 000 & ,000 &., 308 &, 166 & .099 & ,607 & 811 & &, 000 \\
\hline & $\mathrm{N}$ & 94 & 94 & 94 & 94 & 94 & 94 & 94 & 94 & 94 \\
\hline & $\begin{array}{l}\text { Pearson } \\
\text { Correlation }\end{array}$ &, $555^{* *}$ &, $596^{*}$ & .164 & .151 & , 167 &, 135 & .076 & $.755^{\circ}$ & 1 \\
\hline \multirow[t]{2}{*}{ Decision_quality } & Sig (2-tailed) & .000 & .000 & .115 & .145 & .108 &, 196 & .469 & .000 & \\
\hline & $\mathrm{N}$ & 94 & 94 & 94 & 94 & 94 & 94 & 94 & 94 & 94 \\
\hline
\end{tabular}

**. Correlation is significant at the 0.01 level (2-tailed).

*. Correlation is significant at the 0.05 level (2-tailed).

The $\mathrm{R}$ Square indicates how much of the variance in the statistical analysis is explained by the predictor variables: rational, intuitive, dependent, avoidant and spontaneous decision-making style in correlation with the influence on the dependent variable, decision-making style. The reported value for $\mathrm{R}$ square was 0.65 , or $65 \%$. This value takes into account the number of variables included in the statistical analysis. We can hypothesize that our overall research and statistical analysis was significant, but we are not certain whether one or all of our predictor variables is contributing to this result. We have to use the coefficients to find out further influence of the independent variables on decisionmaking speed. The reported Beta value indicates that the regression for decision-making speed is positive or negative. Beta for the rational decision-making style was $0.112(\mathrm{t}=0.772=$ $1.008, \mathrm{p}<0.4)$, for the avoidant decision-making style $(\mathrm{B}=0.087$ $\mathrm{t}(0.99)=0.559, \mathrm{p}<0.6)$ and there was a negative Beta value for spontaneous decision-making $(\mathrm{B}=-0.170, \mathrm{t}(0.107) \mathrm{t}=-1.198$, $\mathrm{p}<0.24)$.

The reported R Square, established the correlation between the observed value and the predicted value of the criterion variable, indicating how much of the variance in the statistical analysis is explained by the predictor variables: rational, intuitive, dependent, avoidant and spontaneous decision-making style in correlation with the influence on the dependent variable, decision quality. The reported value for R square was 0.080 , or $8 \%$.

The Beta coefficient was used to measure of how strongly each predictor variable influenced decision quality. The rational decision-making style had a positive influence on decision quality $(\mathrm{B}=0.204 \mathrm{t}(0.772)=1.858, \mathrm{p}<0.1)$. On the other hand, spontaneous decision-making style had a negative influence on the decision-quality dependent variable $(\mathrm{B}=-0.078 \mathrm{t}(0.104)=-$ $0.553, \mathrm{p}<0.1)$. The $\mathrm{R}$ Square value, reported the relationship between the perceived value and the predicted value of the criterion variable, demonstrating how much of the variance in the statistical analysis is explained by the predictor variables: decision-making speed and decision style in correlation with the positive or negative impact on the dependent variable, incremental marketing innovation $(\mathrm{r}=0.55)$ or $55.7 \%$ in the percentiles.

\subsection{In-coefficients - Decision quality}

The Beta coefficient was used to measure of how strongly each predictor variable influenced incremental marketing innovation. The high Beta value, measured in units of standard deviation, demonstrated a positive impact of the independent decision quality variable on incremental marketing innovation $(\mathrm{B}=0.605$ $\mathrm{t}(0.135)=4.557, \mathrm{p}<0.01)$ The independent decision-making speed variable had a negative influence on incremental marketing innovation $(\mathrm{B}=-0.067 \mathrm{t}(0.132)=-0.501, \mathrm{p}<0.7)$.

The demonstrated correlation between the observed value and the predicted value of the criterion variable, indicating how much of the variance in the statistical analysis is explained by the predictor variables: decision-making speed and decision style in correlation with influence on the dependent variable, radical marketing innovation, reported a $\mathrm{R}$ Square value $(\mathrm{r}=0.362)$ or $36.2 \%$. When there is more than one predictor in the analysis, it odes not suffice to compare the contribution of each predictor variable by merely comparing the correlation coefficients. The Beta coefficient was used to determine the impact of each predictor variable and the influence on radical marketing innovation. The Beta value indicated a positive impact of the independent decision quality variable on radical marketing innovation $(\mathrm{B}=0.502 \mathrm{t}(0.120)=3.927, \mathrm{p}<0.01)$ The independent decision-making speed variable had a positive 
influence on radical marketing innovation $(\mathrm{B}=0.124 \mathrm{t}(0.117)=$ $0.974, \mathrm{p}<0.4)$.

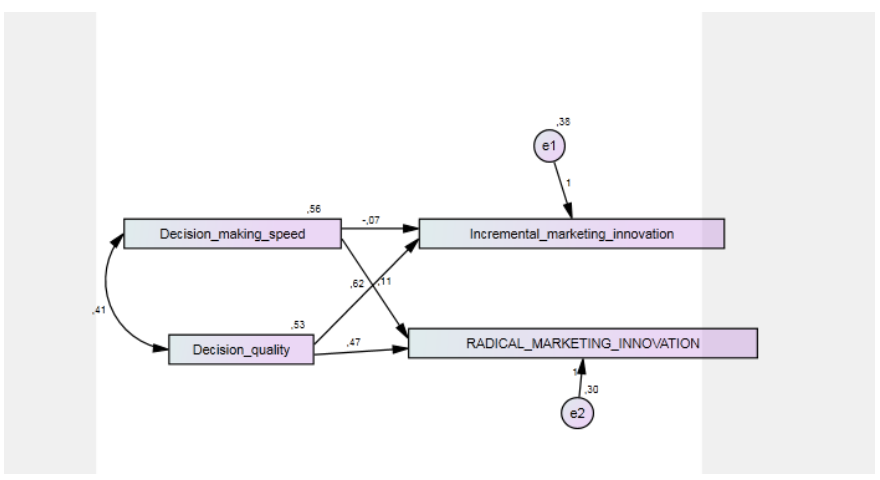

Figure 2: Variable relationship results

In this research, structural equation modeling was used to evaluate nad assess the validity of our analysis and model. To analyze and determine the relations between potential constructs, and also the dependency, structural equation modeling was used to collect unbiased estimates. This was an affirmative structural analysis rather than an exploratory one. The method and procedure of the SEM statistical analysis was conducted by listing of discovered covariance matrix to verify that the model did not converge, testing the parameter values for each variable and finally providing additional information on fit. On the other hand, structural equation modeling, in this study, requires several statistical tests to define the correlation between variables and to determine the adequacy of model fit to the data. In this research, we tried to choose indicators so as to create a latent factor that represents the construct of interest. Maximum likelihood estimates ranged from 0.114 to $0.616,5$ and the negative value was -0.66 .

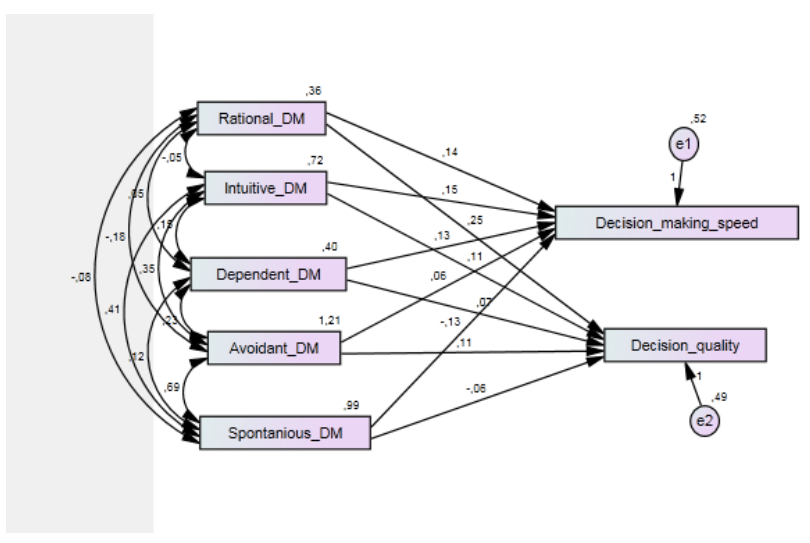

Figure 3: Variable relationship results

\section{Discussion and Implications}

Through our study results, a clear link between decision-making styles and MIS decision-making in terms of quality and speed has been agreed. Five distinctive decision-making styles may influence MIS based decision-making, as well as the use of MIS toward marketing innovation. Spontaneous, rational, dependent, intuitive and avoidant styles of decision-making are deciding factors in the quality and speed of decision-making in organization and also on individual level. The impact of marketing information systems on decision quality and decision speed is very consistent and important. It shortens the time frame for making decisions, creating a correlation between speed and accuracy (correctness) of a decision and also indicates a lack of efficient or inefficient marketing information system processes. The five decision-making styles must show consistency and order in that ambiguity is minimised in the process of structuring information. The relationship between decision-making styles and decision-making quality and speed indicates that decisionmaking styles are able to predict variance in decision-making quality and speed.

In our present research, we tested the hypothesized relationships discussed below.

H1a: Decision quality of information system use positively influence incremental marketing innovation. Which is found to be significant, so we accepted the hypothesis, $(r=0.616$, sig $=0.000$ )

H1b: Decision quality of information system use positively influence radical marketing innovation. Hypothesis $\mathrm{H} 1 \mathrm{~b}$ is significant. Therefore, we accept the hypothesis $(r=0.470$, sig $=0.000$ )

The results exhibit a strong and significant relationship in decision quality. This result is in line with Hamidi and Safabakhsh (2011) posit that information system - quality based decision on marketing information systems - is important to support marketing management in its decision-making, which can be aimed toward marketing innovation. Besides the importance of information system use - quality decision to the management perspective, it can be an essential tool for the entire marketing organization. Some scholars have classified information system in marketing by the tasks for which they are typically used (Wierenga and Ophuis, 1997). Information system use: decision quality was used by Wierenga and Ophuis to develop a framework of marketing and sales productivity (MSP) systems which comprises of four subsystems, namely, the salesperson productivity tools, direct mail, telemarketing and sales management. This can be viewed as marketing innovation through use of information system, which dictates the realization of quality decision.

Quality of decision from information system use influences marketing innovation. The decision maker evaluates the value of information system and direct it toward desired objectives. The information systems literature is rich in studies on the use of information system as a competitive weapon. These studies indicate importance and crucial role that information system plays in marketing innovation. At the same time, studies in the international business literature have examined the strategic forces affecting competition at a global scale as compared to domestic competition and have shown the differences of competitive forces faced by domestic corporations. It seems, however, that both management information system and the 
international management literature have recognized the significance of information system use of quality decisions that are derived from the use of quality information as a facilitator for gaining competitive advantage through marketing innovation in the international environment (Deans and Ricks, 1991). According to Jarvenpaa and Ives, information system is needed to drive marketing innovation activities in a global organization's structure and strategy. Therefore, managing quality decisions about marketing information by the means of information system has become one of the most vital elements of driving effective marketing innovation. This is achieved by collecting and distribution of marketing information to the organizational departments and by using it to promote corporate and brand image to potential customers. Quality decision made offer new ways of cultivating internal efficiencies of an organization. Information systems allow dynamic quality decision communication about new trends in marketing on which business strategies can be aligned and directed in order to attain marketing innovation in the quest of competitive advantage.

H2a: Decision speed of information system use positively influence incremental marketing innovation. Is found to be insignificant $(r=-0.066$, sig=0.618).

H2b: Decision speed of information system use positively influence radical marketing innovation. Decision speed of information system use positively influence incremental marketing innovation system was evident, but did not exhibit an important level of significance $(r=0.114$, sig $=0.333)$. Therefore, we reject the hypothesis.

Decision-making process in an organization consists of two facets: reaching a decision and implementing it. Reaching a decision requires some sort of intelligence, which involves information gathering and processing, then designing which involves formulating and analyzing the decision alternatives, and final choice is made based on the judgments of best alternative to select. While the implementation facet includes the strategies essential to implement and create reached decision from the first facet (Harrison, et al., 1995). Review of literature does not show the difference of decision speed between reaching a decision and implementation. However, in this study, decision speed is totally considered as an important variable toward market innovation.

In dynamic and rapid changing markets, organizations cannot afford to rely on slow or rather relaxed decision-making process if they ought to achieve market innovation in order to outperform competitors. Therefore, achieving market innovation in such environments requires decisions to be speedy. In the study by Bourgeois and Eisenhardt (1988), the crucial feature of the decision processes were identified in their beneficial effect on organizational performance (i.e. market innovation). Other researchers have investigated how decision speed is formed by magnitude of individual uniqueness of decision makers, decision specific factors and external environment. The decision speed in the twentieth century was affected by time constraints and cost of acquiring information before making a decision (Buchanan and Connell, 2006). However, the emergence of information system has enabled theorists to make decisions with an adequate amount of information in an enormous speed.

H3a: Rational decision-making style positively influence decision quality, $(r=0.248$, sig=0.066). The results indicate that rational decision making positively influence decision quality but we reject the hypothesis as it is not significant at ( $\mathrm{sig}<0.05)$.

H3b: Rational decision-making style positively influence decision speed. Hypothesis $\mathrm{H} 3 \mathrm{~b}$ does have positive influence on decision speed but not significant and we therefore reject the hypothesis $(r=0.138$, sig=0.316).

Rational decision-making style had a somewhat positive level of influence on decision quality and decision speed but it proved to be insignificant. The decision makers in rational decision-making style takes time to comprehensively analyze a number of possible alternatives from different scenarios before making a choice. The scenarios are then weighted by probabilities and the decision maker determines the expected outcome or impact of each decision for each alternative. On this basis, the final choice would be for the alternative that presents the finest expected outcome (Oliveira, 2007). Rational decision-making thus presumes that available information enables the decision maker to settle for the best possible alternative. Hence, the rationality is in the essence of selecting which information to order and analyze and which not to (Choo, 2006; Citroen and Hooghoff, 2003; Hussey, 1997; Schwenk, 1986). The decision-making process structured approach is described by the fact that the decision is reached after an extensive search with due attention to a number of distinctive phases that are orderly timed, observed and examined in a rational and objective way.

Consistent with a Parsonian perspective that argues that decisionmaking styles are strategies for solving problems, a rational style which encompasses active and well-calculated plans of decisionmaking activities has been proposed as an ideal strategy (Larson and Gobeli, 1987). Nonetheless, research only partially supports this proposition. Several studies that examined the relationship between a rational style and progress in decision-making on tasks have shown positive or trivial results (Harren et al., 1978; Lunneborg, 1978; Phillips et al., 1984). Individuals that are in rational decision-making style forestall the need to make a decision and prepare for it by seeking relevant information about themselves and their environment before committing to a particular decision. This process has an influence on quality of decision made; there is high probability of making an informed quality decision, however, the speed of decision is likely not to be prompt because of the time span required in gathering information. In rational decision-making style, an individual's main approach to gathering the information and processing it to capture only relevant details is systematic and oriented toward both internal and external sources which contributes heavily to decision quality that consequently leads to marketing innovation (Thunihohm, 2004). The hypotheses tested on intuitive decision are both found to be insignificant at $(P<0.05)$. 
H4a: Intuitive decision-making style positively influence decision quality $(r=0.112$, sig $=0.284)$. Although insignificant but positively influence exist between intuitive and decision quality.

H4b: Intuitive decision-making style positively influence decision speed $(r=0.154$, sig $=0.153)$.

Intuitive decision-making style had a somewhat positive level of influence on decision quality and decision speed but it proved to be insignificant. The decision by an intuitive individual type is made based on the outcome (negative and positive) of previous decisions. Made decision will be used to further form and shape explicit knowledge of decision-making by means of the emotional behavior. Additionally, decision maker in this category is personal (Bierman et al., 2005), which is a feature of the body used to make decisions. According to Patton (2003), there are three sources of intuition used by decision makers when they are trying to handle uncertain and volatile situations of decisionmaking due to rapid and complex changes in the setting. Firstly, it is an elemental response of decision-making which is overseen on decision maker's instinct that produces a subconscious reaction. However, the reactions are usually suitable and applicable to situations that a decision is required to be made. It is inborn and a reaction that cannot be learned. Secondly, general experience involves learning that happens in the normal process of aging in a person's life and in the process of accumulating experience. Finally, focused learning which revolves on learning derives from deliberate effects to develop habits and achieve intuitive reactions. All these affect the decision quality and the speed at which such decisions are made and are a result of these habits and inborn characteristics of the decision-maker.

Intuitive approach to information system use decision-making is primarily based on self-awareness rather than relevant gathered information (Blustein, 1987). According to Phillips et al. (1984), while intuition is likely to include spontaneous decision-making style, an individual feels they have solved a problem or made a decision on the level of control they possess toward solving such a problem or making a decision. The speed of arriving to a decision is rather swift. This is an important scenario of this type of decision-making, necessary for capturing opportunities of strategic windows in the context of marketing innovation. Intuitive decision-making style gained great popularity in recent years although its imprints can be traced back to Chester Barnard (1938). Given that in recent times organizations rely heavily on prompt service delivery, the intuitive approach is regarded as an important factor for speedy decision-making. The role of intuition in decision-making is quite emphasized in literature. It is conceptualized as a two-step process of implicit knowledge in the first stage, which is significant for not only quality but also speed of decision-making.

H5a: Spontaneous decision-making style positively influence decision quality

H5b: Spontaneous decision-making style positively influence decision speed
The results show that spontaneous decision-making style did not have a positive influence on decision quality $(r=0.057$, $s i g=0.582)$ and neither on decision speed $(r=-0.128$, $s i g=0.234)$. We therefore reject hypotheses $\mathrm{H} 5 \mathrm{a}$ and $\mathrm{H} 5 \mathrm{~b}$ as there is no significant influence found on the quality and speed of making decision.

Spontaneous decision-making is impulsive and individuals are prone to make "spur-of-the-moment" or "instant" decisions. Based on this, we can posit that individuals that fit under spontaneous decision-making style better handle marketing circumstances that require speedy decisions. Individuals in this style are characterized by a feeling of immediacy and the desire to get through the decision-making process as quickly as possible (Spicer and Sadler-Smith, 2005). Prior studies on decision speed view prompt action as a decisive competitive weapon for market innovation. Similar studies suggest that decision speed does not lessen decision quality and longer time used to make a decision do not necessarily guarantee or increase decision accuracy (Wilson et al., 1986). Organizations and individuals ability to make such quick decisions is affected by factors within their internal and external environment streamlined toward market innovation. Decision speed achieved by spontaneous decisionmaking style can be a source of competitive edge in the light of subsequent empirical prescriptions of the pursuit of marketing innovation (Bourgeois and Eisenhardt, 1988).

Time is regarded as a scarce organizational resource, which makes decision speed an important consideration in organizational decision-making processes, which complements the information system use. Managers (decision makers) prefer time-based results, which are more beneficial for achieving particular objectives. This also indicates flexibility of an organization towards quality and speed of decision and thus lessens organization's exposure to the uncertainties of external environment (Angwin, 2004).

H6a: Dependent decision-making style positively influence decision quality. This hypothesis is found to positively influence but not significant, so we reject hypothesis H6a $(r=0.071$, $\operatorname{sig}=0.591)$.

H6b: Dependent decision-making style positively influence decision speed. This hypothesis is also found to positively influence but not significant, so we reject hypothesis H6b because it did not exhibit an important level of significance $(\mathrm{r}=0.129$, sig=0.344).

In a reliant style, decision-making accountability is pushed onto external sources, can have a debilitating influence on information system use. Prior studies have revealed that items from the dependent decision-making do not distinguish how or why people involve others. For instance, the decision maker uses recommendation of others in reaching important decisions. Literally, the decision maker rarely take accountability in making important decisions without consulting others. This could imply looking for information and advice from experts to make the best 
decision which is crucial for information system use: decision quality. Moreover, the decision maker can delegate decisions to others that are capable of carrying out the information system tasks; the reason for delegation can be attributed to lack of interest or ability. In the information system framework proposed by Chervany et al., decision effectiveness, which includes quality was found as a part of dependent decision-making.

The decision maker in dependent type of decision-making rely on others for the direction and support. Working toward a common goal as a team, this type of decision-making is interpersonal and intrapersonal, is more of a participative decision-making, which results in a more quality decision. Additionally, the decision might not be quick due to reliance and consultation on others before a final decision is made, however, such decision are less likely to be resisted as other individuals are consulted and aware of the possible outcome of the decision. Dependent decision makers always search for advice and guidance from others before making important decisions (Thunholm, 2004). The processing of using or seeking advice and assistance from others determines the collective background within which decisions made with some people preferring to assign decisions (Finucane et al., 2002; Samsi and Manthorpe, 2011), seek advice, and make decisions with others. Therefore, this decision-making interaction toward information system use has an effect on quality of decision and the speed of making a decision is slow but implementation of such decisions on information system use is prompt

\section{Limitations of the study}

There were numerous limitations to this study in determining the impact of individual decision-making styles on marketing information system based decision-making, which comprehensively, had an impact and influence on the findings of our current research. Initially, when we started to develop our thesis, we took all the potential impediments which may occur during the conducting of our study, but these impediments, did not have a significant influence on the internal and external validity of our overall findings. It is always crucial to acknowledge any possible limitations that may arise when conducting a research and avoid them being pointed out later on, when future research on a similar subject is conducted, which in the end may diminish and lower the value and overall utility of the study. Also, it is vital to highlight, that the acknowledgement and recognition, and therefore acceptance, of a study's limitation is an opportunity to make additional suggestions for further research. This study was carefully elaborated and it was demonstrated that the research problem was carefully thought through and methodically analyzed. All the relevant literature and prior knowledge from various authors who reported on a similar subject or analyzed different elements that were important for our study were analyzed and reported. In analyzing the impact and influence of individual decision-making styles on marketing information system based decision-making, we correctly measured the approaches selected for researching the problem. Main aim of the research process was not only limited to discove new facts and gathering new information but to also confront assumptions and explore the facts which were unknown to us at the time.

Furthermore, as was already aforementioned, it is important to highlight all the key weaknesses of our study and the exact limitations of the present study. Not doing so, extensively diminishes the validity of our research and leaves the researcher wondering and guessing all the various ways and forms in which potential limitations could impact the results and conclusions. This is the reason why limitations require a comprehensive and thorough assessment and interpretation of the impact they had on the research. It is necessary to measure the extent of these restrictions and limitations in order to complete the research.

One limitation this study had encountered was, after the completion of the interpretation of the findings, there was the possibility that the manner in which data was collected, inhibited the ability to conduct a thorough and meticulous analysis of the results. It is crucial to acknowledge this deficiency and point out that future researchers should revise the specific method for gathering data. By eliminating this limitation, it could be easier to address a particular issue that could have emerged later in the research and could indicate some other important and relevant factors which could prove to be important for the study. Selfreporting was another potential limitation of the present study. In analyzing the influence of individual decision-making styles on marketing information system based decision-making, we mostly relied on pre-existing data, along with a combination of collecting the data personally. This can pose a problem considering self-reported data can seldom be independently verified. In our study, we relied on focus groups to which we administered our survey instrument, and these questionnaires results could prove to be unreliable. This occurs because selfreported data can contain potential sources of bias that should be brought to the researcher's attention and perceived as limitations.

\section{Recommendations for Future Research}

In combining all the aforementioned potential limitation of our study with the recommendations for further research, we have come to analyze the possible suggestions which have arisen out of the research limitations and constraints that have been previously identified.

In setting the hypothesized model, we analyzed all the factors and variables which were important and the objectives we set inevitably lead to findings that we did not anticipate right from the start, which is something that can be explored in future studies. In acquiring insight regarding the analysis of personality traits of different managerial levels and the manner they influence decision-making in Saudi Arabia manufacturing companies we have gained new information and overall experience on the marketing information system in Saudi Arabia companies and organization. This valuable data could be further analyzed in future studies and the correlation could be vital in investigating and determining potential relationships of other variables, other than managerial traits, and the impact on the decision-making process. The different factors and variables have 
been supported using previous research and by examining different models constructed in previous studies and they also can be further analyzed using another study which would be conducted another context in order to validate our research model. Along with the existing constructs, avoidant, spontaneous, intuitive and dependent decision-making, it would be significant, for future research, to add new variables to the conceptual framework, but only if justified whether by previous studies or by the findings in this research. Another aspect which is important to highlight, is that future study regarding the influence of managerial traits based on marketing information system on comprehensive decision-making is implementing a different methodology approach, and collecting data by quantifying outputs of marketing information systems, not through survey but using other methods. Various survey methods different methods have different advantages. Other research methods can include telephone interviews, mail correspondence, personal in-home surveys, personal mail or a combination of the above

\section{Conclusion}

Marketing information system (MIS) enables data processing and transformation of data into valuable information that results in a more effective decision-making from which companies benefit. However, human aspect is still an influential factor in the decision-making process. The link between certain individuals' characteristics and their decision-making process is conceptualized. Consequently, the general notion is that marketing information system based decision-making is also impacted by individuals' characteristics. A connection between decision-making styles of employees, inherent in their habits and practices, and marketing innovation system based on the decision-making process is supported. Through a detailed literature review, a link between spontaneous, individual, rational, dependent and avoidant decision-making styles with quality and speed of MIS decision-making has been conceived and constructed. A role of marketing information system in decision-making is empirically tested on a sample of Saudi Arabia manufacturing firms. Data were collected using semistructured interview as well as online questionnaire. The collected data were analyzed using SPSS and SPSS AMOS using inference statistics. Preliminary analysis including assumption and measurement tool testing together with the structural model assessment were performed. Multiple regression model was used in the analysis process. Findings suggest that there is a partial connection between decision-making styles of individuals and the decisions they make based on the marketing information systems. In our study this notion is substantiated through examination of prior literature, and a foundation is built for future exploration. We suggest that decision-making styles influence both quality and speed of the decision-making process. Furthermore, quality and speed of MIS decision-making have a positive influence on radical and incremental marketing innovation. This study enriches the body of literature that focuses on the human-technology interaction and is valuable for companies implementing and using MIS to make business decisions. We recommend that future studies should aim at explaining how individual traits directly influence decisionmaking. Additionally identifying other decision-making types and in what measure they influence the decision-making process is required. Finally, explaining the influence of the marketing information system and the way reach favorable decision-making outcomes is a key aspiration of future research.

\section{References}

- Adler, P. S., \& Borys, B. (1996) Two types of bureaucracy: Enabling and coercive. Administrative Science Quarterly 41(1), 61-89, CrossRef

- Aiken, L. S., \& West, S. G. (1991) Multiple Regression: Testing and Interpreting Interactions. Sage, Newbury Park, CA.

- Avlonitis, G.J. (1985a) Product elimination decision making: Does formality matter? Journal of Marketing 49(1), 41-52, CrossRef

- Avlonitis, G.J. (1986) The identification of weak industrial products. European Journal of Marketing 20(10), 24-42, CrossRef

- Avlonitis, G.J. (1990) Project Drop strap: Product elimination and the product life cycle concept. European Journal of Marketing 24(9), 55-67, CrossRef

- Avlonitis, G.J.(19831984)Improvingproducteliminationinengineeringindustrie s. Journal of General Management 9(2), 42-56.

- Avlonitis,G.J., \& Argouslidis, P.C.(2012)Tracking the evolution of theory on product elimination: Past, present, and future. The Marketing Review 12(4), 345-379, CrossRef

- Avlonitis,G.J.,\& James, B.G.S.(1982)Some dangerous axioms of product elimination decision making. European Journal of Marketing 16(1), 36-48, CrossRef

- Baccarini, D. (1999). The logical framework method for defining project success.Project management journal, (Volume 30), 25-32.

- Bagozzi, R. P., Yi, Y., \& Phillips, L. W. (1991) Assessing construct validity in organizational research. Administrative Science Quarterly 36(3), 421-458, $\underline{\text { CrossRef }}$

- Baum,R.J.,\& Wally,S.(2003) Strategic decision speed and firm performance. Strategic Management Journal 24(11), 1107-1129, CrossRef

- Becker, M. C. (2004) Organizational routines: A review of the literature. Industrial and Corporate Change 13(4), 643-678, CrossRef

- Bluedorn, A. C., Kauffman, C. F., \& Lane, P. M. (1992) How many things do you like to do at once? An introduction to monochronic and polychronic time. Academy of Management Executive 6(4), 17-26, CrossRef

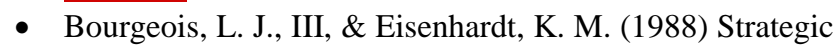
decision processes in high velocity environments: Four cases in the microcomputer industry. Management Science 34(7), 816-835, CrossRef

- Boyle, M. (2013). Unilever plans to reduce product range by further $10 \%$ in 2014. Bloomberg.com, December 5 . <http://www.bloomberg.com/news/2013-12-05/ unileverplans-to-reduce-product-range-by-further-10-in2014.html

- C.H. Mawhiney, A.L. Lederer, A study of personal computer utilization by managers, Information and Management 18, 1990, pp. 243-253, CrossRef 
- Cagwin, D., \& Bouwman, M. J. (2002).The association between activity-based costing and improvement in financial performance. Management Accounting Research, 13(1), 1-39, CrossRef

- Champoux, J. E. (2011) Organizational Behavior. Integrating Individuals, Groups and Organizations (4th ed.). Routledge, New York.

- Chang, Y. Y., \& Hughes, M. (2012) Drivers of innovation ambidexterity in small- to medium-sized firms. European Management Journal 30(1), 1-17, CrossRef

- Chanson, G., \& Quélin, B. V. (2013) Decentralization and contracting out: A new pattern for internal and external boundaries of the firm. European Management Journal 31(6), 602-612. Cottrell, T., \& Nault, B. R. (2004) Product variety and firm survival in the microcomputer industry. Strategic Management Journal 25(10), 10051025.

- Chenhall, R. H. (2003). Management control systems design within its organizational context: findings from contingency-based research and directions for the future. Accounting, organizations and society, 28(2), 127-168, CrossRef

- Chenhall, R. H., \& Langfield-Smith, K. (1998).The relationship between strategic priorities, management techniques, and management accounting: an empirical investigation using a systems approach. Accounting, Organizations and Society, 23(3), 243-264, CrossRef

- Cooper, R., \& Kaplan, R. S. (1992).Activity-based systems: Measuring the costs of resource usage.Accounting Horizons, 6(3), 1-13.

- Cox, W.E.,Jr. (1967) Product life cycles as marketing models. Journal of Business 40(4), 375-384, CrossRef

- D.E. Leidner, J.J. Elam, Executive information systems: their impact on executive decision-making, Journal of Management Information Systems 10 (3), 1993-94, pp. 139- 155, CrossRef

- D.J. Isenberg, How senior managers think, Harvard Business Review 62, 1984, pp. 81-90. [14] D.M.S. Lee, Usage pattern and sources of assistance for personal computer users, MIS Quarterly (1986) 313-325.

- Daft, R. L., \& Lengel, R. H. (1986) Organization information requirements, media richness and structural design. Management Science 32(5), 554-571, CrossRef

- Davenport, T. H. (2013). Process innovation: reengineering work through information technology. Harvard Business Press.

- Davies, D. K., Ilavajhala, S., Wong, M. M., \& Justice, C. O. (2009). Fire information for resource management system: archiving and distributing MODIS active fire data. Geoscience and Remote Sensing, IEEE Transactions on, 47(1), 72-79, CrossRef

- Day, G. S. (1981) The product life cycle: Analysis and applications issues. Journal of Marketing 45(4), 60-67, CrossRef

- Delone, W. H., \& McLean, E. R. (2003).The DeLone and McLean model of information systems success: a ten-year
update.Journal of management information systems, 19(4), 9-30

- Dopuch, N. (1993). A perspective on cost drivers.Accounting Review, 615-620.

- Duhaime, I. M., \& Schwenk, C. R. (1985) Conjectures on cognitive simplification in acquisition and divestment decision making. Academy of Management Review 10(2), 287-295, CrossRef, CrossRef

- Durden, C., \& Pech, R. (2006) the increasing cost of corporate governance: Decision speed-bumps for managers. Corporate Governance 6(1), 84-95, CrossRef

- E.F. Harrison, The Managerial Decision-Making Process, third ed., Houghton Mifflin Company, Boston, 1987.

- Eisenhardt, K. M., \& Bourgeois, L. J., III (1988) Politics of strategic decision making in high-velocity environments: Toward a midrange theory. Academy of Management Journal 31(4), 737-770, CrossRef

- Eisenhardt, K.M.(1989)Making fast strategic decisions in high velocity environments. Academy of Management Journal 32(3), 543-576, CrossRef

- Fayard, D., Lee, L. S., Leitch, R. A., \& Kettinger, W. J. (2012). Effect of internal cost management, information systems integration, and absorptive capacity on interorganizational cost management in supply chains. Accounting, Organizations and Society, 37(3), 168-187, CrossRef

- Forbes, D. P. (2005) Managerial determinants of decision speed in new ventures. Strategic Management Journal 26(4), 355-366, CrossRef

- Fornell, C., \& Larcker, D. F. (1981) Structural equation models with unobservable variables and measurement error: Algebra and statistics. Journal of Marketing Research 18(3), 382-388, CrossRef

- Fredrickson, J. W. (1984) The comprehensiveness of strategic decision processes: Extension, observations, future directions. Academy of Management Journal 27 (3), 445-466, CrossRef

- Fredrickson, J. W., \& Mitchell, T. R. (1984) Strategic decision processes: Comprehensiveness and performance in an industry with an unstable environment. Academy of Management Journal 27(2), 399-423, CrossRef

- G.A. Gorry, M.S. Scott Morton, A framework for management systems, Sloan Management Review (1971) 55-70.

- Galliers, R. D., \& Leidner, D. E. (2014).Strategic information management: challenges and strategies in managing information systems.Routledge.

- Garratt, A., Lee, K., Hashem Pesaran, M., \& Shin, Y. (2003).A Long run structural macroeconometric model of the UK*. The Economic Journal, 113(487), 412-455, CrossRef

- Gault, S. B., \& Jaccaci, A. T. (1996) Complexity meets periodicity. The Learning Organization 3(2), 33-39, CrossRef

- Glazer, R., \& Weiss, A. M. (1993) Marketing in turbulent environments: Decision processes and the time sensitivity 
of information. Journal of Marketing Research 30(4), 509-521, CrossRef

- Grant,J.(2005). Lafley learns from Gillette as P\&G moves to next level. Financial Times, December 21 st.

- Wu, W. W., \& Lee, Y. T. (2007).Selecting knowledge management strategies by using the analytic network process. Expert systems with Applications, 32(3), 841847, $\underline{\text { CrossRef }}$

- Zehir,C.,\& Özşahin, M. (2008)A field research on the relationship between strategic decision making speed and innovation performance in the case of Turkish large-scale firms. Management Decision 46(5), 709-724, CrossRef

- Zimmermann, E. W. (2012). World resources and industries.

- Zsambok, C. E., \& Klein, G. (2014).Naturalistic decisionmaking.Psychology Press. 